\title{
O REUSO DA ÁGUA É UMA QUESTÃO DE CIDADANIA E SUSTENTABILIDADE
}

\author{
Thamires Pereira Okamoto ${ }^{1}$ \\ Mayara Oliveira dos Santos ${ }^{2}$ \\ Eduarda de Lima Bernardes ${ }^{3}$ \\ Valquiria Tereza Valério Martins ${ }^{4}$ \\ Márcia Cristina Souza Gesualdi Candotti ${ }^{5}$
}

Resumo: O trabalho apresentado veio de uma iniciativa de alguns alunos da escola E.E.E.I. Professor Nelson do Nascimento Monteiro que visam melhorias ao meio ambiente, sobre a economia e o reuso da água. $O$ artigo refere-se ao início de uma pesquisa detalhada sobre o uso sustentável dos recursos hídricos e o reuso da água para a produção de material didático sobre a "Água para a Educação Básica" do Projeto Água - "Redevale compartilhando conhecimentos", cujo produto final em andamento poderá ser um folder divulgando como reutilizar a água, a sua finalidade e a importância para o meio ambiente.

Palavras-chave: Recurso natural; Reutilização; Água; Sustentabilidade.

\footnotetext{
${ }^{1}$ E.E.E.I Professor Nelson do Nascimento Monteiro, Brasil. E-mail: tataokamoto77@gmail.com.

2 E.E.E.I Professor Nelson do Nascimento Monteiro, Brasil. E-mail: wffimayara@hotmail.com.

${ }^{3}$ E.E.E.I Professor Nelson do Nascimento Monteiro, Brasil. E-mail: eduardadelima_levita@hotmail.com.

${ }^{4}$ E.E.E.I Professor Nelson do Nascimento Monteiro, Brasil. E-mail: valquiriatvm@gmail.com.

${ }^{5}$ E.E.E.I Professor Nelson do Nascimento Monteiro, Brasil. E-mail: professoramarciabiologia@gmail.com.
} 